\title{
Does Planas' Equiplan really work in deep bite treatment?
}

\author{
Orlando Santiago Júnior \\ Arnaldo Jansen Dental School, Belo Horizonte, MG, Brazil \\ E-mail: osjofm@gmail.com
}

Received 6 December 2021; received in revised form 16 December 2021; accepted 24 December 2021 DOI https://doi.org/10.21595/jfocg.2021.22329

Check for updates

Copyright (C) 2021 Orlando Santiago Júnior. This is an open access article distributed under the Creative Commons Attribution License, which permits unrestricted use, distribution, and reproduction in any medium, provided the original work is properly cited.

\begin{abstract}
Deep bite malocclusion impacts function of the stomatognathic system, patients' quality of life and self-stem by compromising oral and facial esthetics. The malocclusion can involve teeth and facial skeleton, for such is one of the most challenging malocclusion treatments. The aim of this investigation is to check the clinical belief that Planas' Equiplan is efficient to treat deep bite malocclusion. Dental overbite was measured in 21 patients submitting to Jaw Functional Orthopedics treatment at post-graduation course. The inclusion criteria were a vertical trespass of the incisal border of the upper incisors covering the vestibular face of the lower incisors more than $3 \mathrm{~mm}$, treatment cooperation and a consent form signed by the patients, or their legal tutor, allowing the use of the data obtained for research and didactic purposes. The initial measurement (T0) and 15 months treatment (T1) was collected to study overbite behavior during treatment with Planas' Equiplan. The mean overbite of the sample at T0 was 5,02 $\pm 1,311 \mathrm{~mm}$, at T1 the mean overbite was 2,38 $\pm 1,026 \mathrm{~mm}$. The difference T1-T0 is $-2,65 \pm 1,462 \mathrm{~mm}$ $(p<0,01)$. The data presented here supports the efficacy of the use of Planas' Equiplan in the treatment of Deep bite Malocclusion.
\end{abstract}

Keywords: jaw functional orthopedics, deep bite treatment, equiplan, functional orthopedic appliances.

\section{Introduction}

Deep overbite has been considered as one of the most common malocclusion problems that are difficult to be treated and retained. Correction of the deep bite is often a main objective of the orthodontic treatment because of its potentially detrimental effects on periodontal health, temporomandibular joint function, as well as esthetics [1,2]. Prevalence of deep overbite was found to be $21 \%$ to $26 \%$ in the normal population [3], and about $75 \%$ in orthodontic patients [4].

Deep bite is a malocclusion that can have dental or skeletal component. Among the clinical characteristics of deep bite are short anterior lower face height, reduced mandibular angle (skeletal etiology), supra occlusion of incisors/infra occlusion of posterior teeth and deeper curve of Spee (dental etiology) [5].

In a study among Mongolian adolescents Araki et al. [6] found that deep bite and increased overjet malocclusions affect oral health-related quality of life and deep bite malocclusion was significantly associated with oral symptoms and functional limitations. Biomechanical alterations in the Stomatognathic System in individuals with deep bite malocclusion are reported [2, 7-9].

According to Moyers [8] deep bite malocclusion can bring serious aesthetic and functional problems to the individual. It demands, especially when combined with retrognathism, that the facial muscles adapt to abnormal contraction patterns and incisors, due to abnormal occlusal contacts tend to protrude and extrude worsening the deep bite malocclusion. Deep bite malocclusion diagnosis and treatment must not be analyzed only as a dental problem since function and aesthetics are usually compromised by this malocclusion.

Protocols of deep bite correction includes intrusion of incisors, eruption of posterior teeth, extrusion of posterior teeth, orthognathic surgery with the use of mechanical or functional orthopedics and orthodontics [1, 5, 8-15]. 
The Equiplan is an accessory described by Planas as "a stainless-steel plate with 0.3 or $0.4 \mathrm{~mm}$ thickness, $2.5 \mathrm{~cm}$ long by $1.5 \mathrm{~cm}$ wide, with a slight curve and a $1.5 \mathrm{~mm}$ step. It has some retentions on its back to be fixed to the acrylic" [10]. For more information about treatment planning using Equiplan and fixing the equiplan in the functional orthopedic appliances reading of Planas [10], Simões [11], Santiago et al. [12] and Santiago Jr., Santiago [16] is recommended.

In his craniofacial growth and development laws, Planas describes his theory about the Equiplan Modus Operandi. Equiplan arose from the great difficulty of correcting the symptomatology of an exaggerated vertical Deep Bite. "The spectacular result and success in different patients were what was missing to make it available to the professional class" [10].

Jaw Functional Orthopedics (JFO) has a collection of appliances indicated for deep bite treatment that include Bimler's, Planas', Simões', Santiago's appliances among others [10-12]. Planas and Simões stats that deep bite treatment with an Equiplan accoupled in the functional orthopedics appliances improves treatment results. Santiago Jr. et al 2021 presented a functional orthopedic appliance for deep bite (OSS1) with an Equiplan [12]. For many years functional orthopedics appliances, especially the ones with Equiplan are believed to treat deep bite malocclusions with excellence. The aim of this investigation is to check statistically this clinical belief of Equiplan efficacy, with a double-blind study of the behavior of the overbite in millimeters of individuals with deep bite treated with functional orthopedics appliances with Equiplan.

\section{Clinical relevance}

Since deep bite is a prevalent malocclusion that brings functional and emotional negative impacts to the individual, a clinical study about the subject brings more knowledge and clinical tools to help clinicians and patients.

\section{Methodology}

The sample was composed by patients treated in JFO post-graduation in the Brazilian Association of Dentistry - Muriaé - MG. 257 patients, of both sexes were treated, 69 (27\%) patients presented deep bite malocclusion. All the individuals or their legal tutors signed a consent form allowing the use of their treatment data for research and didactic purpose. The students did not know why they are measuring the patients.

Of the 69 patients with deep bite, 22 were treated with functional orthopedic apparatus combined with Equiplan. One of them gave up treatment after 12 months. Regarding gender, 7 patients are male and 14 female, and 1 abandoned treatment after 12 months. The mean age of the sample 16.92, the youngest at 9 years and 1 month of age and the oldest at 39 years and 1 month, both male. An evaluation of treatment efficiency was made after 15 months.

The inclusion criteria were a vertical trespass of the incisal border of the upper incisors covering the vestibular face of the lower incisors more than $3 \mathrm{~mm}$ [17], treatment cooperation and a consent form signed by the patients, or their legal tutor, allowing the use of the data obtained for research and didactic purposes.

There was no control group based on the findings of Dimberg et al. [18] that self-correction of malocclusion from de primary to early permanent dentitions was noted for anterior open bite, sagittal malocclusions, and posterior crossbite, while deep bite developed.

We used the data collected in the individual form of monthly measurements from the date of placement of the Functional Orthopedic Appliance (T0) up to 15 months of treatment with functional orthopedic appliances with Equiplan (T1) (Table 1). The overbite measurements were collected by requesting that the individual close the mouth in the maximum habitual intercuspation position, dry with air jet the vestibular face of the upper and lower incisors and was traced with a pencil on the vestibular face of the lower central incisor the trespass of the incisal edge of the upper central incisor. With the patient with the mouth ajar, the upper part of the caliper is positioned on the incisal border of the lower incisor and the lower part of the caliper in the mark 
obtained. For measuring the overbite analog calipers were used. (Fig. 1).

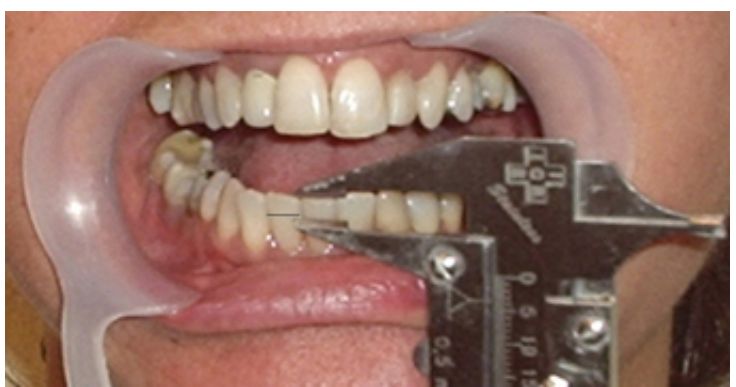

Fig. 1. Overbite measurement

SPSS 11.0 was used in statistical analyses. The assumption of normality was verified through the Shapiro-Wilk test. As the initial and final values of overbite in patients with Deep Bite presented approximately Normal distribution $(p>0.05)$, in the comparison between the means at $\mathrm{T} 0$ and $\mathrm{T} 1$, the t-test for paired samples was used at a significance level of $5 \%$.

Table 1. Overbite measures obtained at $\mathrm{T} 0$ and $\mathrm{T} 1$. Age of patients on the date of functional orthopedic appliance placement

\begin{tabular}{|c|c|c|c|}
\hline Patient & Age - years and months & T0 & $\mathrm{T} 1$ \\
\hline C. C. V. & 14 y $1 \mathrm{~m}$ & 3.5 & 3.0 \\
\hline I. A. P. P. & 11 y $7 \mathrm{~m}$ & 5.0 & 2.5 \\
\hline A. L. P. & 31 y $1 \mathrm{~m}$ & 3.5 & 1.0 \\
\hline M. S. S. & 9 y $1 \mathrm{~m}$ & 3.5 & 3.0 \\
\hline A. A. F. & 12 y $11 \mathrm{~m}$ & 6.0 & 2.0 \\
\hline R. M. C. & 11 y $7 \mathrm{~m}$ & 5.0 & 4.0 \\
\hline E. A. M. & 39 y $1 \mathrm{~m}$ & 6.5 & 1.0 \\
\hline H. S. S. & 16 y $7 \mathrm{~m}$ & 7.0 & 4.0 \\
\hline R. S. V. & 10 y $6 \mathrm{~m}$ & 3.0 & 2.5 \\
\hline L. F. P. & 14 y $3 \mathrm{~m}$ & 6.5 & 4.0 \\
\hline T. M. N. & 11 y $7 \mathrm{~m}$ & 6.0 & 1.9 \\
\hline J. B. R. B. Jr. & 10 y $11 \mathrm{~m}$ & 5.5 & 1.0 \\
\hline S. C. A. & 32 y $8 \mathrm{~m}$ & 3.5 & 1.5 \\
\hline A. S. & 24 y $3 \mathrm{~m}$ & 4.0 & 3.0 \\
\hline J. G. B. & 15 y $7 \mathrm{~m}$ & 4.0 & 1.0 \\
\hline P. M. A. & $12 y$ & 7.5 & 2.5 \\
\hline J. D. M. & 13 y $4 \mathrm{~m}$ & 5.4 & 2.0 \\
\hline M. F. C. B. & 12 y $3 \mathrm{~m}$ & 4.0 & 1.0 \\
\hline T. G. S. & 12 y 3 m & 6.1 & 3.0 \\
\hline S. P. F. & 13 y $11 \mathrm{~m}$ & 5.0 & 3.0 \\
\hline T. J. C. S. & 27 y $1 \mathrm{~m}$ & 5.0 & 3.0 \\
\hline
\end{tabular}

\section{Results}

Table 2 presents the values of initial, final and difference mean and standard deviation for Overbite $(\mathrm{mm})$, and the p-value resulting from the comparison between the means, obtained through the t-test for paired samples. The mean overbite of the sample at T0 was 5,02 $\pm 1,311 \mathrm{~mm}$, at $\mathrm{T} 1$ the mean overbite was $2,38 \pm 1,026 \mathrm{~mm}$. The difference T1-T0 is $-2,65 \pm 1,462 \mathrm{~mm}$ $(p<0,01)$ shows that Planas' Equiplan is an effective tool for deep bite treatment.

Fig. 2 presents the results obtained by the jaw functional orthopedics treatment of deep bite using Planas' Equiplan attached to the functional orthopedic appliance.

The results indicated that the values of overbite $(\mathrm{mm})$ after treatment $(\mathrm{T} 1)$ were statistically lower than the initial (T0) values $(p=0.000)$, besides being closer to zero. The mean difference 
between the final (T1) value and the initial (T0) value was $-2.65 \pm 1.462 \mathrm{~mm}$, indicating that the patients had a reduction in the value of the overbite $(\mathrm{mm})$. The decrease in overbite values means reduction of deep bite (Table 2).

Table 2. Statistical comparison between the initial and final results for Overbite ( $\mathrm{mm})$.

\begin{tabular}{|c|c|c|c|c|}
\multicolumn{4}{|c|}{ Data in mean \pm standard deviation. * Statistically significant difference } \\
\hline & T0 & T1 & Difference (T1-T0) & $p$ \\
\hline Overbite (mm) & $5,02 \pm 1,311$ & $2,38 \pm 1,026$ & $-2,65 \pm 1,462$ & $0,000^{*}$ \\
\hline
\end{tabular}

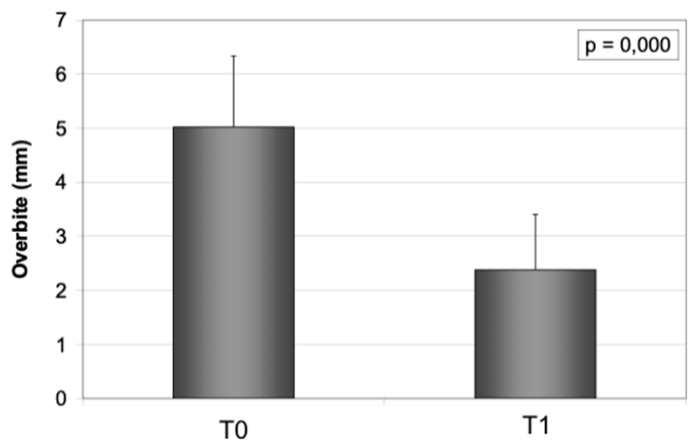

Fig. 2. The mean and standard deviation of the initial (T0) and final (T1) Overbite (mm) values

\section{Discussion}

In the treatment plan of cases with Deep Bite, the following factors should be considered: vertical growth of the face, position of the Occlusal Plane, inclinations of the lower incisors, possibilities of incisor intrusion and mandibular rotation [11]. The Equiplan must be used in the treatment of deep bite basically in two situations. Individuals with short face, or individuals with meso face with severe deep bite. When occurring in individuals with long face the deep bite must be treated with Equiplan in very special situations $[19,20]$. In the treatment of Deep Bite using Equiplan, the direction of growth of the mandible is more important than that of the maxilla to define the use or not of Equiplan [10].

Searching in the literature published in the last two years in Portal Capes, only one article reports the use of raising the bite with disocclusion of posterior teeth. It is case report by Pratiwi and Purwanegara [5] with the use of a removable bite plate. Santiago Jr et al [12] reported a functional orthopedic appliance with equiplan. None of them show any statistic data about treatment effectiveness.

As for non-surgical treatment, two options were presented: orthodontic appliances with or without mechanical orthopedic accessories (like mini-implants, or extraoral appliances, for instance) intruding incisors and/or extruding molars [1, 8, 13-15, 21-23] and functional orthopedic appliances stimulating eruption of posterior teeth and inhibiting eruption of anterior teeth $[5,10-12,19]$.

Extrusion of posterior teeth is controversial. Sakima, Tanne, Sachdeva [22] do not recommend the extrusion of posterior teeth due to the risk of relapse caused by occlusal forces due to the reduction of interocclusal free space. Williams et al [23] recommends the extrusion of superior molars and distal movement to increase the angle of the maxillary and mandibular planes. All the authors that recommend the orthodontic approach [1,8,13-15, 21-23] base in leveling the arch for deep bite correction. According to Planas [10] and Simões [11] the treatment of deep bite with equiplan has the same goal promoting eruption of the posterior teeth. For such Equiplan must be used in long face individuals in very special situations [19].

The Equiplan demonstrated efficiency in deep bite treatment in the short term. Since mandibular rest position adapts to the new occlusal vertical dimension obtained by the treatment 
with Equiplan, it seems that relapse is not very common, but that is another clinical belief that has to be checked with more investigations.

The data obtained is in accordance with Santiago Jr [20] who stated that nothing replaces Jaw Functional Orthopedics in the treatment of vertical problems. Planas [10] and Simões [11] reported deep bite treatment success reporting some cases on their book. The three authors mentioned above, besides no statistical data on their publications, made correct statements proven with the data obtained in this investigation.

According to Simões [11], Equiplan exerts an action of capturing energy through the anterior teeth by repositioning the mandible, allowing eruptive movements and favoring the increase and maintenance of the vertical dimension. As demonstrated by PLANAS [10] Equiplan promotes direct excitation, resulting in an increase in vertical dimension through the lower Occlusal Plane, thus producing a compensatory response in the superior Occlusal Plan. The efficacy of the Equiplan is partially proved here, but these theories by Simões [11] and Planas [10] still need to be checked.

\section{Conclusions}

Equiplan proved to be efficient in the treatment of Deep Bite in the short term.

More investigations are needed to study the long-term effect of Equiplan and its Modus Operandi.

\section{References}

[1] M. M. El Namrawy, F. El Sharaby, and M. Bushnak, "Intrusive arch versus miniscrew-supported intrusion for deep bite correction," Open Access Macedonian Journal of Medical Sciences, Vol. 7, No. 11, pp. 1841-1846, Jun. 2019, https://doi.org/10.3889/oamjms.2019.332

[2] A. A. Gianelly, J. C. Petras, and J. Boffa, "Condylar position and class and class II deep-bite, no-overjet malocclusions," American Journal of Orthodontics and Dentofacial Orthopedics, Vol. 96, No. 5, pp. 428-432, Nov. 1989, https://doi.org/10.1016/0889-5406(89)90328-4

[3] E. Bergersen, "A longitudinal study of anterior vertical overbite from eight to twenty years of age," The Angle Orthodontist, Vol. 58, pp. 237-256, 1988, https://doi.org/10.1043/0003-3219(1988)058

[4] W. Proffit, H. J. Fields, and L. J. Moray, "Prevalence of malocclusion and orthodontic treatment need in the US," International Journal of Adult Orthodontics and Orthognathic Surgery, Vol. 13, pp. 97-106, 1998.

[5] D. Pratiwi and M. Purwanegara, "Deep bite correction with an anterior bite plate in a growing patient," Scientific Dental Journal, Vol. 4, No. 3, p. 129, 2020, https://doi.org/10.4103/sdj.sdj_24_20

[6] M. Araki et al., "Associations between malocclusion and oral health-related quality of life among Mongolian adolescents," International Journal of Environmental Research and Public Health, Vol. 14, No. 8, p. 902, Aug. 2017, https://doi.org/10.3390/ijerph14080902

[7] N. Darendeliler, M. Dincer, and R. Soylu, "The biomechanical relationship between incisor and condylar guidances in deep bite and normal cases," Journal of Oral Rehabilitation, Vol. 31, No. 5, pp. 430-437, May 2004, https://doi.org/10.1111/j.1365-2842.2004.01264.x

[8] R. E. Moyers, Handbook of Orthodontics. 4th Ed., Chicago: Year Book Medical Publishers, 1988.

[9] A. Ari-Demirkaya, S. Biren, H. Özkan, and N. Küçükkeleş, "Comparison of deep bite and open bite cases: normative data for condylar positions, paths and radiographic appearances," Journal of Oral Rehabilitation, Vol. 31, No. 3, pp. 213-224, Mar. 2004, https://doi.org/10.1046/j.0305182x.2003.01236.x

[10] P. Planas, Rehabilitación neuro-oclusal (RNO). 2nd. ed., (in Spanish), Masson Salvat Odontologia, Barcelona, 1994.

[11] W. A. Simões, Ortopedia funzionale dei mascellari Attraverso La Riabilitazione Nuero-Occlusale. 5th Ed., (in Italian), Orbetello, 2010.

[12] O. Santiago Júnior, M. Vedovello Filho, M. V. Lucas Ferreira, and R. Huebner, "Functional orthopedic appliance for vertical dimension increase and mandibular deprogramming Orlando Santiago System 1 - OSS1. Indications and laboratorial manufacturing," Jaw Functional Orthopedics and Craniofacial Growth, Vol. 1, No. 1, pp. 12-17, Jun. 2021, https://doi.org/10.21595/jfocg.2021.22079 
[13] H. Pamukçu and P. Özsoy, "A comparison of treatment results of adult deep-bite cases treated with lingual and labial fixed appliances," The Angle Orthodontist, Vol. 91, No. 5, pp. 590-596, Sep. 2021, https://doi.org/10.2319/011021-29.1

[14] A. Atalla, M. A. Fotouh, F. Fahim, and M. Foda, "Effectiveness of orthodontic mini-screw implants in adult deep bite patients during incisor intrusion. A Systematic Review," Contemporary Clinical Dentistry, Vol. 10, No. 2, pp. 372-381, 2019, https://doi.org/10.4103/ccd.ccd_618_18

[15] M.-H. Jung, "Vertical control of a Class II deep bite malocclusion with the use of orthodontic miniimplants," American Journal of Orthodontics and Dentofacial Orthopedics, Vol. 155, No. 2, pp. 264-275, Feb. 2019, https://doi.org/10.1016/j.ajodo.2018.08.016

[16] O. Santiago Jr. and I. P. M. Santiago, Atlas de Construção de Aparelhos Ortopédicos Funcionais. 1th Ed., (in Portuguese), Ribeirão Preto, Editora Tota, 2010.

[17] L. A. Castro, Modesto, R. Vianna, and V. L. M. Soviero, "Estudo transversal da evolução da dentição decídua: forma dos arcos, sobressaliência e sobremordida," Pesquisa Odontológica Brasileira, Vol. 16, No. 4, pp. 367-373, Dec. 2002, https://doi.org/10.1590/s1517-74912002000400015

[18] L. Dimberg, B. Lennartsson, K. Arnrup, and L. Bondemark, "Prevalence and change of malocclusions from primary to early permanent dentition: A longitudinal study," The Angle Orthodontist, Vol. 85, No. 5, pp. 728-734, Aug. 2015, https://doi.org/10.2319/080414-542.1

[19] O. Santiago Jr, I. P. M. Santiago, and R. C. O. Pedroni, "Tratamento de Distoclusão com Mordida Aberta e com Sobremordida com Ortopedia Funcional dos Maxilares-Diferenças Clínicas e Laboratoriais," in Nova Visão em Ortodontia e Ortopedia Funcional dos Maxilares, 1th ed. (in Portuguese), São Paulo: Livraria Santos Editora Ltda, 2002, pp. 243-259.

[20] O. Santiago Jr., "Diagnóstico em Ortopedia Funcional dos Maxilares e suas Implicações Clínicas," in Odontologia, Conhecimento e Arte: Odontopediatria, Ortodontia e Ortopedia Funcional dos Maxilares, Pacientes Especiais, 1th ed., São Paulo: Editora Artes Médicas, 2003, pp. 185-201.

[21] W. R. Proffit and H. W. Fields Jr., Contemporary Orthodontics. 3rd ed., St Louis: Mosby, 2000, pp. $475-487$.

[22] K. T. T. Sakima and R. Sachdeva, "Correção da Mordida Profunda, Considerações Clínicas e Bimecânicas,” (in Portuguese), Ortodontia, Vol. 35, No. 4, pp. 289-296, 1987.

[23] J. K. Williams, P. A. Cook, K. G. Isaacson, and A. R. Thom, Fixed Orthodontic Appliances: Principles and Practice. 1st. ed., Oxonia: Butterworth-Heinemann, 1995.

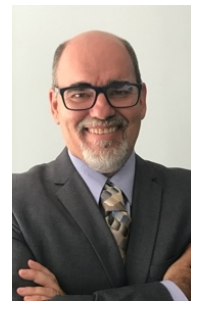

Orlando Santiago Júnior is a Ph.D. student in Mechanical Engineering (Department of Mechanical Engineering) Universidade Federal de Minas Gerais Belo Horizonte, MG, Brazil. Now he works at dental office and is Associate professor at School of Dentistry at Faculdade Arnaldo Jansen, and School of Dentistry. His current research interest includes Jaw Functional Orthopedics, Temporomandibular Disorders, Dental Occlusion and Bite Force Measurement, bioengineering, nanomaterials 